\title{
A Trilogia Matrix e o Ensino de Tecnologia
}

The Matrix Trilogy and Technology Teaching

\author{
Marcos A. Costa ${ }^{1}$ \\ Antônio V. dos Santos ${ }^{2}$
}

\section{Resumo}

Em um mundo dinâmico e repleto de alternativas, as formas de aprendizado mais inovadoras devem ser incentivadas e aplicadas de forma coerente para que o discente sinta maior interesse pelos conteúdos curriculares. À medida que o aluno observa tais conteúdos, não apenas através de analogias, mas também por meio de uma produção cinematográfica, a qual possui referências e influências das mais diversas, podemos encontrar várias informações que contemplam um auxílio, principalmente, ao aprendizado tecnológico, percorrendo estudos matemáticos, físicos, filosóficos e religiosos. Isto também se dá através de uma inovação conceitual, de nossa parte, que diz respeito ao ensino ser classificado coerentemente como uma transmissão de conhecimentos e não de valores como alguns autores tentam estabelecer. Sendo assim, nesta abordagem torna-se possível não apenas fazer com que determinados alunos identifiquem-se mais com o tema, pois já têm uma tendência natural pela tecnologia e as linhas dos filmes, mas também se pode promover o aprendizado daqueles que não são íntimos dos assuntos.

Palavras-chave: Matrix, Ensino, Tecnologia.

\section{Abstract}

In a world full of dynamic and alternative forms of learning more innovation should be encouraged and applied consistently so that the student feel more interest in curriculum content. As the student observes such content not only through analogies, but also through production film, which has references and influences from different sources, we can find various information that include mainly the technological learning, not excluding mathematics, physics, philosophy and religious studies. We make it possible through a concept innovation of teaching which is described, coherently, as a knowledge transmission and not as broadcasting of values as some authors try to argue. So, with this approach is possible, not only, to make that some students identify themselves more with the theme, because they have a natural tendency for technology and another areas, but also can promote the learning of those who do not have such intimacy with these areas.

Keywords: Matrix, Learning, Technology.

\footnotetext{
${ }^{1}$ URI - Universidade Regional Integrada do Alto Uruguai e Missões - Campus Santo Ângelo, RS | mcostax@gmail.com

${ }^{2}$ URI - Universidade Regional Integrada do Alto Uruguai e Missões - Campus Santo Ângelo, RS | vandao@santoangelo.uri.br
} 


\section{Introdução}

O processo de ensino-aprendizagem tem sido pouco modificado desde sua principal metodologia na Grécia antiga, no entanto, considerando nossa inserção em um mundo que é extremamente dinâmico e pouco atrativo aos conteúdos necessários para a nossa evolução intelectual, principalmente nas áreas chamadas duraras, devemos procurar por desenvolver tecnologias que ultrapassem as barreiras burocráticas governamentais e que possam ser inovadoras de tal forma que o próprio governo também possa se beneficiar delas e por consequência toda a sociedade.

Atualmente não devemos mais nos perguntar se devemos ou não introduzir novas tecnologias da informação e comunicação no processo educacional, já nos anos 1980 os educadores preocupados com esta questão consideraram inevitável que a tecnologia invadisse a educação e a escola, acabando por atingir toda a nossa sociedade (MONTEIRO \& REZENDE, 1993). Já há algum tempo, mais precisamente na década de 1990, os professores de várias áreas reagiram de maneira mais radical, reconhecendo que, se a educação e a escola não abrissem espaço para essas novas tecnologias, elas poderiam ter seus espaços definitivamente comprometidos (KAWAMURA, 1998).

Sabemos, entretanto, que por si sós estes meios não são capazes de trazer contribuições para a área educacional, ou ao menos é o que poderíamos pensar atualmente. Porém, se virmos a tecnologia não como sendo o componente mais importante do processo educativo, mas como uma ferramenta essencial para que a técnica educacional seja otimizada ao máximo, ela certamente terá seus objetivos atingidos de forma mais plena e sincronizada com a realidade em que vivemos (COSTA, 2012).

É certo que devemos perceber que a tecnologia educacional deve adequar-se às necessidades de determinado projeto político-pedagógico, colocando-se a serviço de seus objetivos e nunca determinando-os, de acordo com Carraher (1992).

Já pensando de outra forma, desde que usadas como fundamento do processo de ensino-aprendizagem e não como mero instrumento, Pretto (1996) admite, numa visão oposta, que as novas tecnologias podem representar uma nova forma de pensar e sentir ainda em construção, vislumbrando, assim, um papel importante para elas na elaboração do pensamento.

Porém, independente disto, por estarmos inseridos em um mundo altamente dinâmico e, no entanto, com seus programas pedagógicos idealizados pelo governo, os vemos como lentos e engessados por uma burocracia e interesses escusos à sociedade que anseia por uma educação de maior qualidade disponível ao maior número possível de cidadãos.

A introdução das ciberculturas, em todos os níveis etários e educacionais, não pode mais ser ignorada (PIASSI, 2008 e SILVA, 2008). A utilização do cinema na educação traz uma nova perspectiva que atrai a atenção dos alunos (SILVA, FERREIRA, MENDONÇA, ANDRADE, 2005). Uma das áreas mais exuberantes é o uso da ficção científica, pois exerce fascínio nos alunos não só pela imagem e efeitos especiais, mas também por todo contexto surreal que acaba despertando nos mesmos uma possível comparação com a realidade (SILVA, FERREIRA, MENDONÇA, ANDRADE, 2005). Isto também nos fascina e nos motiva fortemente a estudar e propor a utilização da ficção cientifica na sala de aula, tanto como 
um motivador quanto como uma proposta de dinamizar as aulas com evolução dos conceitos tecnológicos.

Ou seja, o uso de filmes como motivação no ensino já possui algumas pesquisas em andamento, sendo mais específico o uso de filmes de ficção científica como uma forma didática de ensino (PIASSI, 2007 / PIASSI, 2008 / PIASSI, 2009 / SILVA, FERREIRA, MENDONÇA, ANDRADE, 2005).

Sendo assim, um dos marcos do cinema de ficção foi a trilogia Matrix, a qual foi uma revolução visual pós-moderna que causou muita discussão sobre seus novos conceitos, desafiando-nos a utilizar este filme com propósitos educacionais, discutindo a evolução de seus conceitos tecnológicos e atraindo ainda mais os alunos à discussões sobre a concepção da estrutura tecnológica atual.

O artigo esta dividido em seções onde primeiramente entendemos melhor a metodologia proposta no trabalho e, logo após, são apresentamos alguns fatos da trilogia.

\section{Metodologia}

A metodologia de pesquisa e observação foi baseada na Observação Naturalística (BAKEMAN, 1986 e MANN, 1991), conceituada como um método que envolve um investigador que observa os acontecimentos tomando notas dos mesmos assim que acontecem. Tal observação pode ser direta, onde o investigador acompanha os fatos, ou indireta, onde o investigador fica sabendo de fatos através de recursos como narrativas, por exemplo.

A Observação Naturalística se beneficia do fato de permitir que o observador visualize o que os personagens fazem inseridos em um contexto, no entanto, permitindo que o mesmo dê maior ênfase e atenção em áreas de interesse específicas, além de possibilitar a observância sistemática dos acontecimentos, assim como estabelecer relacionamentos entre fatos e/ou personagens ao mesmo tempo em que reforça as relações entre causas e efeitos.

Desta forma, e com base nesta metodologia, acompanhamos a trilogia completa como fatos verossímeis devidamente encaixados e adaptados à Observação Naturalística, permitindo que nossas análises e respectivas anotações possibilitassem que os capítulos a seguir se tornassem extremamente relevantes e permitindo a continuidade deste trabalho.

\section{Fatos da Trilogia e sua relação com outras obras}

Matrix, o primeiro filme da trilogia, foi lançado em 31 de março de 1999, sob a direção e autoria de Larry e Andy Wachowski, e foi um grande sucesso de bilheteria e crítica. Desde a sua concepção o mesmo foi idealizado como uma trilogia, no entanto, para sua criação teve de ser pensado também economicamente.

Para tanto, o filme foi produzido com continuidade condicional, ou seja, se o primeiro filme obtivesse sucesso econômico, não apenas de crítica, a trilogia teria incentivo a 
continuar, caso contrário não. ${ }^{3}$ Porém, com o primeiro filme sendo um sucesso e visualmente revolucionário, principalmente devido a efeitos como o "bullet time" ${ }^{\prime 4}$, exposto de forma mais direta com demonstração de todo o poder visual deste recurso, a franquia ganhou força e seus criadores, os irmãos Wachowski, resolveram produzir o segundo (Matrix Reloaded) e o terceiro (Matrix Revolutions) filmes ao mesmo tempo, dando um intervalo apenas nas datas de lançamento que se deram nos dias sete de maio e cinco de novembro de 2003 respectivamente.

Matrix (1999) possui muitas referências a cultura cyberpunk ${ }^{5}$ e hacker6, a idéias filosóficas e religiosas assim como homenagens a Alice no País das Maravilhas ${ }^{7}$, Spaghetti Westerns ${ }^{\&}$, speedRacer'e animes japoneses ${ }^{10}$, sendo que, a história da trilogia como um todo tem suas principais influências no filme Dark City ${ }^{11}$ (1998) e da história de Simulacron$3^{12}$ (1964). De Dark City, de onde são tiradas ideias, como por exemplo, da sobrenaturalidade da personagem principal totalmente desconhecida pelo mesmo e sendo despertada através de outras figuras que acreditam nele, além das referências de parasitas e consciência coletiva, ambos os aspectos vistos no comportamento das máquinas e programas da Matrix.

No entanto, de Simulacron-3 são tiradas as ideias de virtualidade e interoperacionalidade entre o mundo virtual e real. No livro, há uma cidade gerada por computador tão bem programada que seus habitantes têm sua própria consciência, assim

${ }^{3}$ O problema da continuidade condicional é um problema recorrente em Hollywood, mesmo que o filme seja sucesso de crítica e se ele não for uma produção independente com recursos consideráveis dificilmente a continuação sairá do papel, como, por exemplo, o ocorrido com o filme Sky Captainand World ofTomorrow (2004) (Sky Captain e o Mundo de Amanhã, no Brasil), cujo sucesso de crítica foi enorme, porém, foi muito mal economicamente, pois não arrecadou, nem levando em consideração a bilheteria mundial, o custo total da produção do filme (RottenTomatoes, 2013/IMDB, 2013).

4 Efeito Visual cujo conceito antecede a própria invenção do cinema, onde EadweardMuybridge utilizava câmeras fotográficas posicionadas ao longo de uma pista para capturar fotos de um cavalo galopando.

Cinematograficamente há referências ao conceito como em The Returnofthe Pink Panther (A Volta da Pantera Cor-de-rosa, no Brasil) de 1975, nas cenas de luta em câmera lenta entre o Inspetor Clouseau e Cato, e também há referências da utilização da técnica, porém de forma sutil se comparado a Matrix, como em Blade (Blade - O Caçador de Vampiros, no Brasil) de 1998 e WingCommander (sem tradução para o Brasil) de 1999.

5 Gênero de ficção científica de personagens com vida social e econômica pobre, no entanto, com conhecimento e uso pleno de alta tecnologia (KETTERER, 1992).

${ }^{6}$ Programadores Computacionais e Analistas de Sistemas com habilidades de invasão digital com fins de visualização e ou reparo de problemas de segurança. Já o cracker é o hacker com fins de destruição e lesão do invadido (RAYMOND, 2000).

${ }^{7}$ Alice'sAdventures in Wonderland (1865), escrita por Charles LutwidgeDodgson sob o pseudônimo Lewis Carroll (BBC, 2013).

${ }^{8}$ Filmes do gênero Western produzidos na década de 60 na Europa, principalmente na Itália (WIKI, 2013).

${ }^{9}$ Seqüência de abertura de desenho produzido entre 1967 e 1968.

${ }^{10}$ Desenhos animados produzidos no Japão.

11 Filme escrito e dirigido por Alex Proyas. Atores: Rufus Sewell, William Hurt, Kiefer Sutherland e Jennifer Connelly.

${ }^{12}$ Também publicado como Counterfeit World, por Daniel F. Galouye, um dos livros de ficção científica pioneiros na abordagem da realidade virtual. Tal livro originou dois filmes: um filme alemão do tipo conceito feito para TV chamado WeltamDraht (World on Wires / Mundo nos Fios - tradução literal) de 1973, dirigido por Rainer Werner Fassbinder, e o filme The ThirteenthFloor, de 1999 (O $13^{\circ}$ andar, no Brasil), com direção de Josef Rusnak e atuação de Craig Bierko e Armin Mueller-Stahl, que obteve maior visibilidade e sucesso. 
como a inteligência artificial programada na Matrix. Vê-se, então, também que, tanto em Simulacron-3 quanto na Matrix há a imersão completa do usuário no mundo virtual, onde até mesmo se o indivíduo morrer virtualmente, devido ao grau de imersão no mundo virtual irá morrer também no mundo real.

Este fenômeno é verificado, também, em outro título literário: The Lawnmower Man ${ }^{13}$ (1975), e em outro título televisivo: The Menagerie - Partes I e II ${ }^{14}$ de Star Trek: The Original Series. Porém, assim como em Simulacron-3, no segundo filme da trilogia (Matrix Reloaded, 2003), uma das cópias da consciência eletrônica do Agente Smith do programa da Matrix, também consegue a inversão de planos, onde a consciência eletrônica acaba assumindo um corpo real e substituindo a consciência do corpo físico, fazendo assim com que uma consciência eletrônica tenha vida no mundo real.No entanto, os motivos da imersão virtual em ambos os conceitos são diferentes já que em Simulacron-3 não há a guerra entre o homem e a máquina.

Em Matrix (1999), a imersão virtual dá-se devido a explicações que não são fornecidas completamente no decorrer dos filmes da trilogia, mas sim nas séries animadas chamadas Animatrix ${ }^{15}$ (2003). Matrix (1999) tem como tema a luta do ser humano, por volta do ano de 2200, para se livrar do domínio das máquinas que evoluíram após o advento da Inteligência Artificial. Como uma medida extrema para derrotar as máquinas, a humanidade cobre a luz do Sol para cortar o suprimento de energia das mesmas, mas elas adotam uma solução radical levando em consideração que cada ser humano produz, em média, 120 volts de energia elétrica. Assim, as máquinas começam a cultivar seres humanos em massa como fonte de energia e para que o cultivo fosse eficiente, os seres humanos passaram a receber programas de realidade virtual, enquanto seus corpos reais permaneciam mergulhados em habitáculos nos campos de cultivo. Esta realidade virtual, que é um programa de computador ao qual todos estão conectados, chama-se Matrix e simula a humanidade do final do século XX.

O último refúgio da humanidade encontra-se, então, em Zion, uma cidade real perto do centro da Terra, onde se escondem os seres humanos livres que se lançam em missões para a Matrix, para combater as máquinas e libertar mais humanos. Para tal, os humanos livres são imersos, então, no mundo da Matrix, por vontade própria através de um

\footnotetext{
13 Obra de Stephen King, publicada primeiramente com o nome de Cavalier em 1975 e compilada em uma breve história em 1978 com o nome de Night Shift. Também foi produzido um filme em 1992 (O Passageiro do Futuro, no Brasil). Tal história fala sobre uma pessoa comum que recebe imersão em um mundo computadorizado que supre seus sentidos e aguça sua inteligência, sendo que posteriormente sua consciência é imergida integralmente para o meio digital.

${ }^{14}$ Dois episódios da série original que foram ao ar em 17 e 24 de novembro 1966, escrito, produzido e dirigido por Gene Roddenberry, e discorriam sobre a imersão completa do consciente sob um mundo de ilusões. Este tipo de acontecimento é visto com menor grau de imersão, porém, com frequência a partir de Star Trek - The Next Generation, no capítulo EncounteratFairpoint (de 28 de setembro de 1987), no Holodeck, um deque que provê experiências criadas por computador providas pela replicação de matéria, raios tratores, campos de força e projeção de imagens.

${ }^{15}$ Coleção de nove filmes animados que explicam de forma mais definitiva a origem e o desenrolar da trama de Matrix (1999).
} 
dispositivo físico de conexão direta com o virtual ${ }^{16}$, porém, estes humanos são devidamente treinados para saberem como lidar com este mundo virtual com vantagens sobre outros indivíduos da Matrix, como super velocidade, pulos gigantescos e habilidades de luta fora do padrão.

Sabendo disto, a partir do segundo filme há um confronto mais intenso entre o homem e máquina para a completa aniquilação do inimigo. Entretanto, Morpheus* ${ }^{\star}$ desde o primeiro filme, através de contato com o Oráculo*, passa a acreditar no Escolhido ${ }^{17}$, que estaria na pessoa de $\mathrm{Neo}^{\star}$ e seria o único a ter condições de salvar Zion das máquinas falando direto com o Arquiteto*e com poderes muito além dos humanos libertos, como desviar de balas, voar e ver tudo como linhas de código, sabendo como tudo se dá realmente na Matrix e demonstrando a "digital rain" (chuva digital), onde há referência direta ao filme Ghost in the Shell(1995) $)^{18}$.

\section{Análises e discussão}

As nossas análises são iniciadas na tabela 1 (capítulo 5), onde encontramos uma riqueza inestimável de personagens e perfis. Começamos, então, por explorar a personagem principal. Esta personagem pode ser melhor compreendido quando em aulas de programação, discutindo o perfil do programador, assim como o contexto social onde um programa pode atuar. Além do mais, este pode ser utilizado em aulas de ciência sociais onde pode ser discutida a moral e a ética na informática.

Ocorre, também, certa relação com temas religiosos a partir do momento em que se acredita que Neo é o escolhido, fazendo uma clara alusão ao cristianismo, onde João Batista anuncia Cristo.

Outras discussões também são possíveis, à medida que a tecnologia das naves, tal como a do pulso eletromagnético, pode ser utilizada para debates a respeito da teoria eletromagnética em cadeiras intimamente relacionadas com cursos de engenharia física e informática. Ao mesmo tempo, a existência do Agente Smith cria uma fácil relação com disciplinas de segurança de sistemas computacionais e de rede, já que ele tem o papel de controlador e regulador da Matrix.

Cypher é uma personagem que, de acordo com suas características, pode ser associado a um vírus que pode danificar certos ambientes de forma disfarçada, no entanto, para as ciências sociais sua semelhança passa a se dar com Judas Escariotes, o qual trai seus aliados.

Ainda nas ciências sociais pode ser destacado certo poder de divindade ao Arquiteto que seria o criador da Matrix, e ao Oráculo, que seria um profeta, que seria o que poderia

\footnotetext{
${ }^{16}$ Uma cadeira especial que possui um plug de conexão que liga-se diretamente ao cérebro e a medula espinhal através de orifícios feitos cirurgicamente para total imersão à Matrix.

${ }^{17}$ Referência a um messias que se sacrificaria em benefício da humanidade, fato verificado no último filme da trilogia Matrix Revolutions (2003).

${ }^{18}$ Anime japonês dirigido por Mamoru Oshii e escrito por Kazunori Ito de uma adaptação dos quadrinhos de Masamune Shirow.

* Ver tabela na parte "Os Personagens da Trilogia" deste artigo.
} 
elucidar os novos caminhos. No entanto, com relação às ciências exatas, o Arquiteto seria o designer de todo o sistema como ele foi concebido para funcionar e o Oráculo seria um analisador estatístico com tendências para mudança, ou seja, permitir que a Matrix seja modificada, nem que para isto determine seu fim.

\section{As personagens da trilogia}

Tabela 1: Perfis das personagens

\begin{tabular}{|l|l|l|}
\hline Personagem & Ator & Descrição Direta da Personagem \\
\hline $\begin{array}{l}\text { Thomas A. } \begin{array}{l}\text { Anderson } \\
\text { Neo }\end{array} \\
\text { Morpheus }\end{array}$ & Keanu Reeves & $\begin{array}{l}\text { É um programador de computadores que se esconde virtualmente, já } \\
\text { imerso em um mundo virtual dentro da Matrix, como o hacker de } \\
\text { pseudônimo Neo. }\end{array}$ \\
\hline Trinity & Carrie-Anne Moss & $\begin{array}{l}\text { Humano libertado da Matrix, capitão da nave Nebuchadnezzar } \\
\text { (Nabucodonosor). Ele é quem encontra Neo e Ihe conta a verdade } \\
\text { sobre a Matrix. }\end{array}$ \\
\hline Libententada por Morpheus é o interesse romântico de Neo. \\
\hline Cypher & Hugo Weaving & $\begin{array}{l}\text { Agente da Matrix. É um programa com o único propósito de destruir } \\
\text { Zion e impedir os humanos de fugir da Matrix, mas que } \\
\text { diferentemente dos outros agentes possui ambições de se libertar de } \\
\text { suas obrigações por interesses próprios, como, por exemplo, dominar } \\
\text { o mundo das máquinas também (aspecto verificado no terceiro filme } \\
\text { da série, Matrix Revolutions de 2003). }\end{array}$ \\
\hline Oráculo & Joe Pantoliano & $\begin{array}{l}\text { Humano libertado por Morpheus. Acaba traindo Morpheus em troca } \\
\text { de voltar a viver na Matrix. Sua idéia principal era de que ele preferia } \\
\text { viver uma doce mentira na Matrix do que amargar a vida real em Zion. }\end{array}$ \\
\hline Arquiteto & Gloria Foster / Mary & $\begin{array}{l}\text { Programa exilado da Matrix que ainda reside na mesma, ajudando os } \\
\text { humanos libertos com suas previsões e sabedoria. }\end{array}$ \\
\hline
\end{tabular}

\section{A História da Trilogia e o Ensino}

Antes de continuarmos, devemos esclarecer uma dúvida que pode acontecer quando estamos educando ou ensinando. A educação é o processo de transferência e aquisição de valores enquanto, enquanto o ensino é o processo de transferência e aquisição de conhecimentos e conhecimento é o conjunto de saberes cientificamente comprovados.

Assim, podemos ver que existe diferença entre os dois conceitos e, desta forma, é possível ver que alguns profissionais da área não dominam este conhecimento, isto fica claro quando foi realizado o levantamento bibliográfico desse trabalho. A legislação afirma que cabe à família a transferência de valores, logo, considerando o fato de que os valores não podem ser ensinados e sim obtidos durante a vida do individuo, não é tarefa do professor educar e, sim, ensinar.

Neste ínterim, podemos constatar nossa inovação já a partir do momento em que não usaremos o termo educação e sim ensino, ou seja, utilizando a trilogia Matrix para ensinar conceitos e não valores. 
A utilização de filmes de ficção científica e de filmes populares está sendo uma ferramenta utilizada com certa frequência em sala de aula. A era digital nos fornece riqueza no sentido da popularização do cinema na sala de aula (CLAREMBEAUX, 2010).

Visto isto, verificamos que o ensino tecnológico a partir da trilogia Matrix é bem entusiasmante, não apenas para aqueles que gostam de técnicas inovadoras para o ensino, mas também para aqueles que buscam estabelecer conexões de maior proximidade entre o docente e o discente de forma mais agradável e ligada à contemporaneidade, como a exibição de filmes que tenham algo a contribuir com o ensino.

Outro lado que pode ser explorado na utilização de filmes de ficção científica é o do extremo uso de tecnologia em si empregado na produção dos mesmos. A exploração de tecnologias visuais em Matrixcomo, por exemplo: bullet time, interpolação ${ }^{19}$ e a própria renderização ${ }^{20}$ dos efeitos realizada em um cluster $^{21}$ FreeBSD $^{22}$.

Desta forma, também tecnologias de construção de jogos também podem ser exploradas, até mesmo porque a franquia gerou 3 jogos eletrônicos desde o seu lançamento sendo eles: Enterthe Matrix (2003), produzido pela Atari, do tipo FPS; The Matrix Online (2004), produzido pela Warner Bros. InteractiveEntertainment, do tipo MMORPG ${ }^{24}$;e The Matrix: Path ofNeo (2005), da Atari, do tipo Ação e Adventure ${ }^{25}$.

A história da trilogia Matrix não é inteiramente original, no entanto, no decorrer do filme são perceptíveis várias analogias a conceitos do mundo da informática que foram construídos baseados no próprio mundo real.

Nos capítulos que seguem, de acordo com cada filme da trilogia, tentaremos identificar as analogias que podem ser feitas para um melhor entendimento de conceitos de tecnologia, matemática, física, filosofia e religião. Ou seja, estamos modernizando a utilização de filmes, para a transferência de conhecimento e não de valores, demonstrando momentos dos filmes e a possível transferência de conceitos, sendo este quadro auto explicativo e proporcionando uma utilização pelo professor em sala de aula, com a possibilidade de eventuais interrupções propositais de acordo com os conteúdos que devem ser ministrados pelo docente.

${ }^{19}$ Método que permite construir um novo conjunto de dados a partir de um conjunto discreto de dados pontuais previamente conhecidos. Através da interpolação, pode-se construir uma função que aproximadamente se "encaixe" nestes dados pontuais, conferindo-Ihes, então, a continuidade desejada(WIKI, 2013). Desta forma, pode-se garantir maior fluidez de movimentos na câmera lenta.

20 Processo pelo qual pode-se obter o produto final de um processamento digital qualquer. Este processo aplica-se essencialmente em programas de modelagem 2D e 3D, bem como áudio e vídeo(WIKI, 2013).

${ }^{21}$ Aglomerado de computadores, que utiliza uma configuração especial de um sistema operacionalque suporte tal característica e classifique-o como sistema distribuído. Muitas vezes é construído a partir de computadores convencionais os quais são ligados em rede e comunicam-se através do sistema, trabalhando como se fossem uma única máquina de grande porte.

22 Sistema operacional livre do tipo Linux descendente do BSD Unix desenvolvido pela Universidade de Berkeley.

${ }^{23}$ First-Person Shooter (tiro em primeira pessoa): é um estilo de jogo de computador no qual se enxerga apenas o ponto de vista do protagonista, como se o jogador e personagem do jogo fossem o mesmo observador.

${ }^{24}$ Massive Multiplayer Online Role-Playing Game: jogo de interpretação de personagem online em massa para múltiplos jogadores, ou seja, é um jogo de computador que permite a milhares de jogadores criarem personagens em um mundo virtual dinâmico ao mesmo tempo na Internet sem paradas.

${ }^{25}$ Tipo de jogo caracterizado pela exploração dos cenários, pelos enigmas e quebra-cabeças (os chamados "puzzles"), pela interação com outros personagens e pelo foco na narrativa. 


\section{The Matrix (1999)}

Tabela 2: Descrição de conceitos que podem ser explorados nas cenas do The Matrix (1999)

\begin{tabular}{|c|c|c|}
\hline Momento(s) & O que ocorre & $\begin{array}{l}\text { O que pode ser verificado para } \circ \text { aprendizado e } \\
\text { analogias }\end{array}$ \\
\hline $\begin{array}{l}3: 00 / 1: 46: 30 / \\
1: 49: 30 / 1: 55: 00 / / \\
2: 05: 00\end{array}$ & Efeito Bullet Time. & $\begin{array}{l}\text { Conceitos e cálculos matemáticos e físicos sobre como } \\
\text { ele foi realizado nas filmagens reais e modelagem de } \\
\text { ambientes em 3D quando realizado digitalmente. }\end{array}$ \\
\hline $\begin{array}{l}3: 30 / \\
3: 59: 00 / \\
1: 53: 00 / 1: 59: 00\end{array}$ & $\begin{array}{l}\text { Comunicação } \\
\text { Morpheus. }\end{array}$ & $\begin{array}{l}\text { Realizada pelo telefone, assim como em uma conexão } \\
\text { com redes é necessário um dispositivo de conexão e } \\
\text { assim como na internet atual a mesma se dá através de } \\
\text { telefones. }\end{array}$ \\
\hline $5: 40$ & $\begin{array}{l}\text { Saída da Matrix (ocultada até } \\
\text { o momento). }\end{array}$ & Desconexão do sistema. \\
\hline $8: 30$ & $\begin{array}{l}\text { Visualização de Simulacron } \\
\text { em um livro oco. }\end{array}$ & Referência literária sobre a principal inspiração. \\
\hline 10:00/18:20 & Conversa Hacker. & $\begin{array}{l}\text { Conversa de cultura cyberpunk e hacker posta em } \\
\text { diálogos condizentes com a realidade dos personagens. }\end{array}$ \\
\hline 21:40 & $\begin{array}{l}\text { Agentes da Matrix aplicam } \\
\text { um rastreador no corpo de } \\
\text { Neo (grampo). }\end{array}$ & $\begin{array}{l}\text { É como um log, um tipo de registro das operações } \\
\text { realizadas pela entidade monitorada, item comum em } \\
\text { Sistemas Operacionais e de } E R P^{26} \text { (Enterprise Resource } \\
\text { Planning), também chamada de auditoria. }\end{array}$ \\
\hline 23:00 & O grampo é removido. & $\begin{array}{l}\text { É utilizado um dispositivo que analogamente pode ser } \\
\text { encarado como um removedor específico de spyware }\end{array}$ \\
\hline $27: 30$ & $\begin{array}{l}\text { Conversa a respeito da } \\
\text { Matrix. }\end{array}$ & Revisão do conceito de cidade virtual. \\
\hline 30:00 & Pílula vermelha. & $\begin{array}{l}\text { Um tipo de programa p/ug-in }{ }^{28} \text { que permite que uma } \\
\text { função específica seja realizada, como sair da Matrix, na } \\
\text { história. Desconexão completa apenas através de } \\
\text { logout }\end{array}$ \\
\hline 38:00 & $\begin{array}{l}\text { Conversa a respeito do sinal } \\
\text { pirata para conexão com a } \\
\text { Matrix. }\end{array}$ & $\begin{array}{l}\text { Através de um determinado tipo de conexão, com ou } \\
\text { sem fio, utilizaçãa de métodos de invasão a sistemas de } \\
\text { forma a permanecerem ocultos, ou seja, sem que o } \\
\text { sistema principal tenha muitos recursos para rastrear a } \\
\text { invasão. }\end{array}$ \\
\hline 39:30 & Programa de Construção. & $\begin{array}{l}\text { Referência direta a linguagens de programação } \\
\text { computacional orientadas a objeto onde métodos do } \\
\text { tipo constructor são chamados para alocar recursos } \\
\text { necessários ao funcionamento do objeto o qual fora } \\
\text { requerida uma nova instância, ou seja, a concretização } \\
\text { de uma classe }{ }^{30} \text {. }\end{array}$ \\
\hline
\end{tabular}

${ }^{26}$ Sistema de Gestão Empresarial ou SIGE, que integram todos os dados e processos de uma organização em um único sistema (WIKI, 2013).

${ }^{27}$ É um programa que recolhe informações sobre o usuário e os envia a uma entidade externa sem o seu conhecimento e/ou consentimento. É, assim, como cavalos de tróia e vírus um tipo de malware. Tal termo vem de malicious software que são programas destinados a se infiltrar em um sistema de forma ilícita com o propósito de danificar ou roubar informações (WIKI, 2013).

${ }^{28}$ Adiciona funções a programas maiores (WIKI, 2013).

${ }^{29}$ Saída registrada de um sistema.

30 Define os métodos e os estados possíveis de objetos através de atributos. Em outros termos, uma classe descreve os serviços providos por seus objetos e quais informações eles podem armazenar(WIKI, 2013). 


\begin{tabular}{|c|c|c|}
\hline Momento(s) & O que ocorre & $\begin{array}{l}\text { O que pode ser verificado para } \circ \text { aprendizado e } \\
\text { analogias }\end{array}$ \\
\hline 40:30 & $\begin{array}{l}\text { Explicação de Morpheus } \\
\text { sobre o que é real, onde o } \\
\text { mesmo diz que a realidade } \\
\text { são apenas sinais elétricos } \\
\text { interpretados pelo cérebro. }\end{array}$ & Verificação filosófica. \\
\hline $42: 00$ & Matrixé um software & Matrixé um programa de simulação. \\
\hline 48:00 / 1:47:30 & $\begin{array}{l}\text { Aprendizado com método } \\
\text { muito mais eficiente. }\end{array}$ & $\begin{array}{l}\text { Através de um dispositivo de imersão física completa e } \\
\text { de programas especialistas a eficiência do aprendizado } \\
\text { teoriza-se, neste momento do filme, como } \\
\text { extremamente eficiente. }\end{array}$ \\
\hline 49:30 / 1:06:00 & $\begin{array}{l}\text { Sparring Simulation Program } \\
\text { e Red Dressed Woman. }\end{array}$ & $\begin{array}{l}\text { Outros programas de simulação. Percebe-se que tudo } \\
\text { que compõe a matrix, a exceção dos humanos, são } \\
\text { programas que podem ser escritos por terceiros com o } \\
\text { tanto que respeitem determinadas regras, assim como } \\
\text { funciona a programação de sistemas e partes de } \\
\text { sistemas baseados na Licença GPL }{ }^{32} \text {. }\end{array}$ \\
\hline $56: 30$ & $\begin{array}{l}\text { Matrix possui programas } \\
\text { sencientes }^{33} \text {. }\end{array}$ & $\begin{array}{l}\text { Auge da Inteligência Artificial, porém, muitos filósofos, } \\
\text { particularmente Colin McGinn, acreditam que a } \\
\text { senciência não poderá jamais ser entendida, não } \\
\text { importa quanto progresso seja feito pela neurociência } \\
\text { na compreensão do funcionamento do cérebro (WIKI, } \\
\text { 2013). }\end{array}$ \\
\hline 1:00:00 & $\begin{array}{l}\text { EMP } \quad \text { (Eletromagnetic } \\
\text { Pulse) }\end{array}$ & Explicação e compreensão do fenômeno físico. \\
\hline 1:03:30 & Explicação sobre a comida. & $\begin{array}{l}\text { Vem ao encontro da realidade explicada por Morpheus, } \\
\text { anteriormente (40:30). }\end{array}$ \\
\hline 1:08:00 & $\begin{array}{l}\text { Cypher deixa telefone } \\
\text { ligado. }\end{array}$ & $\begin{array}{l}\text { O telefone ligado, assim como na realidade, permite a } \\
\text { localização através da triangulação, no entanto, na } \\
\text { Matrix, o mesmo pode ser verificado como uma porta } \\
\text { de localização que fora aberta. }\end{array}$ \\
\hline 1:19:00 & Falha Dejavú. & $\begin{array}{l}\text { Conhecimento de uma pequena falha de sincronização } \\
\text { de dados ocorrida na Matrix, quando há atualização da } \\
\text { mesma que é realizada sempre on-the-fly }{ }^{35} \text {. }\end{array}$ \\
\hline 1:19:30 / 1:29:00 & $\begin{array}{l}\text { Morte por desconexão com } \\
\text { a Matrix. }\end{array}$ & $\begin{array}{l}\text { Corte da conexão de dados, incapacitando a } \\
\text { comunicação entre o usuário e o servidor. No filme a } \\
\text { imersão é tal que resulta na morte do usuário, justificada } \\
\text { por: "Sem mente o corpo não existe". }\end{array}$ \\
\hline $1: 20: 00$ & $\begin{array}{l}\text { Os agentes da Matrix } \\
\text { assumem pessoas locais. }\end{array}$ & $\begin{array}{l}\text { Eles agem como vírus infectando pessoas e programas } \\
\text { que passam a agir como eles determinam, mas } \\
\text { permanecem com a sua aparência, ou seja, são } \\
\text { detectáveis explicitamente (como as assinaturas dos } \\
\text { vírus }^{36} \text { ) por qualquer um na Matrix, no entanto, a morte }\end{array}$ \\
\hline
\end{tabular}

\footnotetext{
${ }^{31}$ Programa de computador.

${ }^{32}$ General Public License (Licença Pública Geral).

${ }^{33}$ Capacidade de sofrer ou sentir prazer ou felicidade.

${ }^{34}$ Pulso de alta energia de largo espectro que gera um campo elétrico defasado de um campo magnético, cuja frente de onda pode danificar componentes eletrônicos de estado sólido inseridos no campo em questão.

${ }^{35}$ Atualização em tempo de execução, ou seja, enquanto o sistema roda completamente, assim sendo, sem a necessidade de reinicialização do mesmo, porém, geralmente alguns serviços têm de ser reinicializados após o término da atualização.

${ }^{36}$ Uma seqüência de caracteres que o representa para identificação.
} 


\begin{tabular}{|c|c|c|}
\hline Momento(s) & O que ocorre & $\begin{array}{l}\text { O que pode ser verificado para } 0 \text { aprendizado e } \\
\text { analogias }\end{array}$ \\
\hline & & $\begin{array}{l}\text { do infectado não resulta na morte do vírus, pois o } \\
\text { mesmo permanece em outra entidade. }\end{array}$ \\
\hline 1:25:00 / 2:05:30 & $\begin{array}{l}\text { Visualização do Código pelo } \\
\text { Operador. }\end{array}$ & $\begin{array}{l}\text { Através de um acesso pirata o código da Matrix pode } \\
\text { ser visualizado, assim como o código em debug }{ }^{37} \text {. }\end{array}$ \\
\hline 1:37:00 & $\begin{array}{l}\text { Conversa de Smith com } \\
\text { Morpheus. }\end{array}$ & $\begin{array}{l}\text { Smith comenta com Morpheus a discussão filosófica de } \\
\text { que somos um tipo de vírus para o planeta, e que Smith } \\
\text { seria a cura. }\end{array}$ \\
\hline 1:51:00 & $\begin{array}{l}\text { Efeito de interpolação e } \\
\text { fluidez gráfica. }\end{array}$ & $\begin{array}{l}\text { Conceitos e cálculos matemáticos e físicos para criação } \\
\text { dos efeitos em ambientes em 3D. }\end{array}$ \\
\hline 2:06:30 & Smith é "eliminado". & $\begin{array}{l}\text { Neo comporta-se como um vírus e assume, não mata } \\
\text { Smith, e a Matrix não reconhecendo sua morte não } \\
\text { pôde apagá-lo, no entanto, é um acontecimento } \\
\text { verificado apenas em Matrix Reloaded (2003). }\end{array}$ \\
\hline
\end{tabular}

\section{Matrix Reloaded (2003)}

Tabela 3: Descrição de conceitos que podem ser explorados nas cenas do Matrix Reloaded (2003)

\begin{tabular}{|c|c|c|}
\hline Momento(s) & O que ocorre & $\begin{array}{l}\text { O que pode ser verificado para } 0 \text { aprendizado e } \\
\text { analogias }\end{array}$ \\
\hline $\begin{array}{l}\text { 1:30 / 2:30 / 10:20 } \\
/ \text { / } 56: 30 / 1: 19: 00 / \\
1: 40: 20 / 1: 53: 00 / \\
1: 53.40\end{array}$ & Efeito Bullet Time e Fluidez. & Ver primeiro item de Matrix, tabela anterior. \\
\hline $6: 30$ & $\begin{array}{l}\text { Problemas no sinal de } \\
\text { transmissão nos túneis. }\end{array}$ & Conexões sem fio \\
\hline 9:00 / 1:11:30 & $\begin{array}{l}\text { Neo é chamado de anomalia } \\
\text { e outros seres anômalos. }\end{array}$ & $\begin{array}{l}\text { Uma anomalia computacional seria o resultado de algo } \\
\text { inesperado inerente a programação da entidade } \\
\text { relacionada. Em Matrix causam flutuçes na equação. }\end{array}$ \\
\hline 9:30 & $\begin{array}{l}\text { A capacidade de luta dos } \\
\text { agentes é incrementada e } \\
\text { Neo as chama de upgrades. }\end{array}$ & $\begin{array}{l}\text { Seria uma atualização em si, tornando o software } \\
\text { atualizado mais adequado a novas situações e } \\
\text { realidades. }\end{array}$ \\
\hline 10:30/32:00 & $\begin{array}{l}\text { Cópias e assimilações de } \\
\text { Smith. }\end{array}$ & $\begin{array}{l}\text { Estabelecimento de comportamento de vírus } \\
\text { computacional muito mais agressivo. }\end{array}$ \\
\hline $31: 30$ & Smith se dá por Bane. & $\begin{array}{l}\text { Conceito referenciado em The Thirteenth Floor (1999) } \\
\text { onde a Inteligência Artificial e a imersão física no } \\
\text { ambiente virtual são tais que a consciência eletrônica de } \\
\text { Smith consegue substituir a consciência de Bane, } \\
\text { humano liberto que foi pego por Smith antes da } \\
\text { desconexão. }\end{array}$ \\
\hline $34: 30$ & $\begin{array}{l}\text { Conversa de Neo com } \\
\text { integrante do Conselho. }\end{array}$ & $\begin{array}{l}\text { Dilema e ironia: "máquinas permitindo que possamos } \\
\text { viver (perto do centro da Terra), enquanto, outras } \\
\text { querem nos matar". }\end{array}$ \\
\hline 41:30 & Corredor de portas. & $\begin{array}{l}\text { Portas em informática são responsáveis pela entrada e } \\
\text { saída de dados e acesso a programas e a código } \\
\text { escondido e restrito com ocorrência de back doors }{ }^{38} \text {. }\end{array}$ \\
\hline
\end{tabular}

${ }^{37}$ Debug ou depuração é o processo de encontrar e reduzir erros de um programa, onde se pode visualizar informações inerentes a programas e processos particulares e seu comportamento com Sistema Operacional. 


\begin{tabular}{|c|c|c|}
\hline Momento(s) & O que ocorre & $\begin{array}{l}\text { O que pode ser verificado para } \circ \text { aprendizado e } \\
\text { analogias }\end{array}$ \\
\hline 45:00 & $\begin{array}{l}\text { Conversa de Neo com o } \\
\text { Oráculo. }\end{array}$ & $\begin{array}{l}\text { Programas hackeando programas para evitarem serem } \\
\text { deletados. Outro jeito seria indo direto ao código } \\
\text { fonte }^{39} \text {. }\end{array}$ \\
\hline 47:30 & Referência ao Chaveiro. & $\begin{array}{l}\text { O chaveiro (keymaker) seria um programa do tipo Key } \\
\text { Server }^{40} \text {. }\end{array}$ \\
\hline 49:00 & Smith quer dominar tudo. & $\begin{array}{l}\text { Um vírus que tenta disseminar-se em todo o ambiente } \\
\text { tentando dominá-lo por completo. }\end{array}$ \\
\hline $52: 00$ & $\begin{array}{l}\text { Briga no parque entre Neo e } \\
\text { Smith após conversa com o } \\
\text { Oráculo. }\end{array}$ & Cenas de luta feitas 100\% em 3D. \\
\hline 1:00:00 & $\begin{array}{l}\text { Neo verificando o código da } \\
\text { Matrix, mas achando } \\
\text { estranho, talvez estivesse } \\
\text { encriptado. }\end{array}$ & Uso de criptografia ${ }^{41}$. \\
\hline 1:02:30 & $\begin{array}{ll}\text { Apresentação } & \text { de } \\
\text { Merovingian, o chefe } & \text { do } \\
\text { Chaveiro na Matrix. } & \\
\end{array}$ & $\begin{array}{l}\text { Merovingian é um programa traficante de informações, } \\
\text { um tipo de net sniffer }{ }^{42} \text {. }\end{array}$ \\
\hline 1:14:00 & Espectros Anômalos. & $\begin{array}{l}\text { Programas interativos com o ambiente virtual que, } \\
\text { porém, conseguem temporariamente ignorar os limites } \\
\text { tridimensionais. }\end{array}$ \\
\hline 1:17:00 / 1:18:45 & $\begin{array}{l}\text { Tele-transporte através de } \\
\text { portas de acordo com a } \\
\text { vontade do seu dono. }\end{array}$ & Uso de $N A T^{43}$ \\
\hline 1:31:30 & $\begin{array}{l}\text { Agentes são entidades para } \\
\text { deletar as anomalias. }\end{array}$ & $\begin{array}{l}\text { Tentando acabar com as flutuações na equação da } \\
\text { Matrix. }\end{array}$ \\
\hline 1:32:45 & $\begin{array}{l}\text { Neo salvando o Chaveiro e } \\
\text { Morpheus. }\end{array}$ & $\begin{array}{l}\text { Efeitos visuais diversos: bullet time, interpolação e } \\
\text { fluidez. A cena da explosão do caminhão tem um nível } \\
\text { alto de detalhe e foi } 100 \% \text { produzida digitalmente. }\end{array}$ \\
\hline 1:34:00 / 1:41:00 & Prédio com um andar o qual & Funcionamento de um Firewal/ $f^{44}$. C Chaveiro da Matrix \\
\hline
\end{tabular}

${ }^{38}$ Falha de segurança que pode existir em um programa de computador ou sistema operacional, que pode permitir a invasão do sistema (WIKI, 2013).

${ }^{39}$ Conjunto de palavras ou símbolos escritos de forma ordenada e estruturada, contendo instruções de uma linguagem de programação, de maneira lógica (WIKI, 2013).

40 Provê chaves criptográficas (arquivos de autenticidade de entidades) para usuários e programas para trabalharem no mesmo sistema garantindo acesso e restrição a usuários.

${ }^{41}$ Técnicas pelas quais a informação pode ser transformada da sua forma original para outra ilegível, de forma que possa ser conhecida apenas por seu destinatário (detentor da "chave secreta"), o que a torna difícil de ser lida por alguém não autorizado. Atualmente, nos dados digitais a criptografia é basicamente feita por algoritmos que fazem o embaralhamento dos bits desses dados a partir de uma determinada chave ou par de chaves, dependendo do sistema criptográfico(WIKI, 2013).

42 Software capaz de interceptar e registrar o tráfego de dados em uma rede de computadores. Conforme o fluxo de dados trafega na rede, o sniffer captura cada pacote e eventualmente decodifica e analisa o seu conteúdo de acordo com o protocolo definido em um RFC (Request for Comments - documento que descreve os padrões de cada protocolo da internet) ou uma outra especificação.

O sniffing pode ser utilizado com propósitos maliciosos por invasores que tentam capturar o tráfego da rede com diversos objetivos, dentre os quais podem ser citados, obter cópias de arquivos importantes durante sua transmissão, e obter senhas que permitam estender o seu raio de penetração em um ambiente invadido ou ver as conversações em tempo real (WIKI, 2013).

${ }^{43}$ Network AddressTranslation: técnica que consiste em reescrever os endereços IP de origem de um pacote que passam por um roteador ou firewall de maneira que um computador de uma rede interna tenha acesso a uma rede externa (WIKI, 2013). 


\begin{tabular}{|c|c|c|}
\hline Momento(s) & O que ocorre & $\begin{array}{l}\text { O que pode ser verificado para } 0 \text { aprendizado e } \\
\text { analogias }\end{array}$ \\
\hline & $\begin{array}{l}\text { possui muitas portas que } \\
\text { levam a muitos lugares } \\
\text { conhecidos e escondidos, e } \\
\text { também podem levar a } \\
\text { fonte. }\end{array}$ & $\begin{array}{l}\text { serve como alguém que garantiria acesso irrestrito a } \\
\text { qualquer parte do sistema. }\end{array}$ \\
\hline 1:34:30 & $\begin{array}{l}\text { Comentário sobre a falha } \\
\text { sistêmica de um prédio. }\end{array}$ & $\begin{array}{l}\text { Um prédio seria um sistema construído sobre outros, e } \\
\text { assim, caso um sistema externo como o elétrico falhar, o } \\
\text { sistema do prédio falha também, assim todos os seus } \\
\text { subsistemas. }\end{array}$ \\
\hline 1:45:00 & 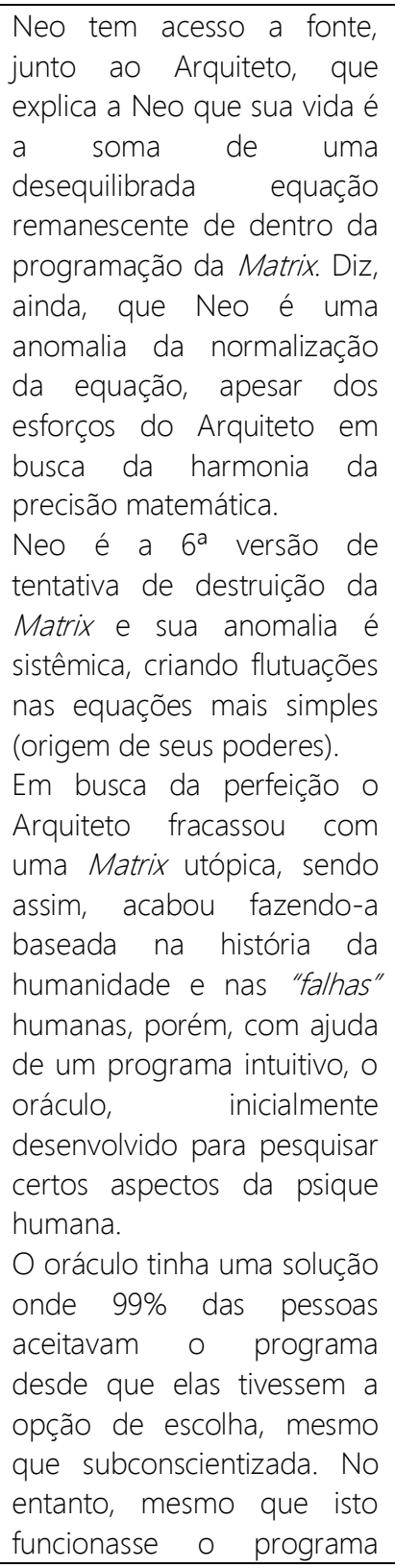 & $\begin{array}{l}\text { Visualização de programas inteligentes e independentes } \\
\text { realizando suas funções causando conflitos. Verificação } \\
\text { de conceitos filosóficos, paradoxais e de referências } \\
\text { messiânicas. }\end{array}$ \\
\hline
\end{tabular}

${ }^{44}$ Programa que tem por objetivo aplicar uma política de segurança a um determinado ponto de controle da rede regulando o tráfego de dados entre redes distintas e impedindo a transmissão e/ou recepção de acessos nocivos ou não autorizados de uma rede para outra (WIKI, 2013). 


\begin{tabular}{|c|c|c|}
\hline Momento(s) & O que ocorre & $\begin{array}{l}\text { O que pode ser verificado para o aprendizado e } \\
\text { analogias }\end{array}$ \\
\hline & $\begin{array}{l}\text { ainda teria uma falha } \\
\text { fundamental, criando, deste } \\
\text { modo, uma falha sistêmica } \\
\text { que de outro modo seria } \\
\text { contraditório que sem } \\
\text { supervisão poderia colocar o } \\
\text { sistema em perigo. Assim, } \\
\text { aqueles que rejeitam o } \\
\text { programa, ainda que uma } \\
\text { minoria, sem supervisão } \\
\text { criaram uma grande } \\
\text { probabilidade de acontecer } \\
\text { um desastre e possibilitar } \\
\text { que alguns expandam em } \\
\text { muitos seus limites na Matrix, } \\
\text { assim como Neo. } \\
\text { Verifica-se também neste } \\
\text { encontro que a função do } \\
\text { Escolhido (Neo) seria } \\
\text { retornar a fonte permitindo } \\
\text { a disseminação temporária } \\
\text { do código que carrega, } \\
\text { reinserindo assim o } \\
\text { programa primário. Depois } \\
\text { disto, ele deve escolher } 16 \\
\text { mulheres e } 7 \text { homens na } \\
\text { Matrix para reconstruir Zion. } \\
\text { O fracasso neste processo } \\
\text { resultaria num colapso } \\
\text { cataclísmico que mataria a } \\
\text { todos na Matrix. }\end{array}$ & \\
\hline 1:58:30 & EMP (Eletromagnetic Pulse). & Ver 1:00:00 de Matrix (1999) na tabela anterior. \\
\hline 1:59:45 & $\begin{array}{l}\text { Neo destrói sentinelas } \\
\text { dos domínios da Matrix. }\end{array}$ & $\begin{array}{l}\text { Discussão sobre dois pontos de vista: } \\
\text { - Neo sobreviveria ao ataque pois também consegue ser } \\
\text { uma anomalia no plano das máquinas, ou seja, a dita } \\
\text { realidade poderia ser apenas mais um nível de abstração } \\
\text { da realidade criada por outras máquinas; } \\
\text { - Neo sobreviveria ao ataque pois as máquinas tem em } \\
\text { seu código algo que as impede de destrú-lo e entrarem } \\
\text { em curto já que a reinicialização do sistema seria algo } \\
\text { inerente a programação da Matrix. }\end{array}$ \\
\hline
\end{tabular}

${ }^{45}$ Soldados de batalha da Cidade das Máquinas que tentam destruir Zion e as naves dos humanos que tentam invadir a Matrix. 


\section{Matrix Revolutions (2003)}

Tabela 4: Descrição de conceitos que podem ser explorados nas cenas do Matrix Revolutions (2003)

\begin{tabular}{|c|c|c|}
\hline Momento(s) & O que ocorre & $\begin{array}{l}\text { O que pode ser verificado para o aprendizado e } \\
\text { analogias }\end{array}$ \\
\hline $3: 00$ & $\begin{array}{l}\text { Sobrenaturalidade de Neo, } \\
\text { pois o mesmo conectou-se a } \\
\text { Matrix sem estar plugado } \\
\text { fisicamente. }\end{array}$ & $\begin{array}{l}\text { Continuidade da discussão proposta no final de Matrix } \\
\text { Reloaded (2003) em 1:59:45 da tabela anterior. }\end{array}$ \\
\hline $4: 30$ & $\begin{array}{l}\text { Trainman, contrabandeia } \\
\text { programas para fora e para } \\
\text { dentro da Matrix. }\end{array}$ & $\begin{array}{l}\text { Um tipo de software que adere programas e pessoas em } \\
\text { seus domínios de forma discreta ao sistema da Matrix. }\end{array}$ \\
\hline $9: 30$ & $\begin{array}{l}\text { Na Matrix todo programa } \\
\text { deve ter um propósito, } \\
\text { senão será deletado. }\end{array}$ & Propósito de um programa. \\
\hline $\begin{array}{lll}17: 40 / / & 1: 44: 30 / \\
1: 50: 30 & \\
\end{array}$ & Efeitos de bullet time. & Verificação dos Efeitos Visuais. \\
\hline 28:00 & $\begin{array}{l}\text { O Oráculo comenta que o } \\
\text { propósito do Arquiteto é } \\
\text { equilibrar a equação e o do } \\
\text { Oráculo é desequilibrar a } \\
\text { mesma equação da Matrix. }\end{array}$ & Verificação do propósito de cada indivíduo. \\
\hline $51: 00$ & $\begin{array}{l}\text { Smith mostra que conseguiu } \\
\text { sair da Matrix para assassinar } \\
\text { Neo. }\end{array}$ & $\begin{array}{l}\text { Consciência Artificial assumindo um corpo do mundo } \\
\text { real. }\end{array}$ \\
\hline 58:00 & $\begin{array}{l}\text { Uso das APUs (Armored } \\
\text { Personnel Unit - unidade de } \\
\text { armadura pessoal) }\end{array}$ & $\begin{array}{l}\text { Um tipo de armadura controlada manualmente por um } \\
\text { humano, no entanto, com uso de tecnologia que } \\
\text { possibilita maior força e utilização de armamento } \\
\text { pesado. Referência cinematográfica inicial ao filme Aliens } \\
(1986)^{46} \text {. }\end{array}$ \\
\hline 1:30:00 / 1:54:00 & $\begin{array}{l}\text { Novamente Neo mostra } \\
\text { poder fora da Matrix e } \\
\text { chega até a Cidade das } \\
\text { Máquinas e diz ao Senhor } \\
\text { das Máquinas para parar } \\
\text { temporariamente o ataque a } \\
\text { Zion pois Smith quer } \\
\text { controlar tudo e em breve } \\
\text { irá dominar toda a Matrix e } \\
\text { somente Neo pode detê-lo. } \\
\text { Se Neo ganhar, pede a paz, } \\
\text { caso contrário, ele pode } \\
\text { matá-lo. } \\
\text { Neotenta mas não consegue } \\
\text { sobrepujar Smith, no } \\
\text { entanto, o fracasso de Neo } \\
\text { era inevitável, assim como o } \\
\text { fim do propósito de Smith e, } \\
\text { desta forma, Smith preso a }\end{array}$ & $\begin{array}{l}\text { Cumprimento sistemático de cada parte de um sistema } \\
\text { resultando no equilíbrio final desejado. } \\
\text { A assinatura viral do vírus é identificada e a desinfecção } \\
\text { é realizada sem a corrupção de quaisquer programas ou } \\
\text { arquivos infectados. }\end{array}$ \\
\hline
\end{tabular}

${ }^{46}$ Dirigido por James Cameron, continuação de Alien (1979), com Sigourney Weaver, CarrieHenn, Michael Biehn, Lance Henriksen, and Bill Paxton. 


\begin{tabular}{|c|c|c|}
\hline Momento(s) & O que ocorre & $\begin{array}{l}\text { O que pode ser verificado para } 0 \text { aprendizado e } \\
\text { analogias }\end{array}$ \\
\hline & $\begin{array}{l}\text { uma regra básica da Matrix. } \\
\text { Smith é eliminado, pois não } \\
\text { tem mais a proteção de Neo } \\
\text { e como não há mais } \\
\text { anomalias para eliminar seu } \\
\text { propósito acabou. A Matrix, } \\
\text { então, deleta-o } \\
\text { sumariamente baseado em } \\
\text { suas próprias regras. }\end{array}$ & \\
\hline 1:58:30 & $\begin{array}{l}\text { O Oráculo pergunta ao } \\
\text { Arquiteto se os outros que } \\
\text { ainda estão conectados à } \\
\text { Matrix serão libertados. O } \\
\text { Arquiteto confirma que sim, } \\
\text { no entanto, O Oráculo } \\
\text { desconfia e rapidamente o } \\
\text { Arquiteto pergunta, em } \\
\text { seguida: "O que acha que } \\
\text { sou? Humano?" }\end{array}$ & $\begin{array}{l}\text { Investigação de questões da psique humana. O que } \\
\text { realmente nos faz sermos humanos. }\end{array}$ \\
\hline
\end{tabular}

\section{Considerações Finais}

Através da realização desse trabalho podemos tirar algumas conclusões. Uma que nos saltou aos olhos, lendo algumas referências e na realização da revisão bibliográfica os autores ainda confundem os conceitos de ensino e educação assim deixando ainda um vasto caminho a ser percorrido pelo uso de filmes tanto na educação quanto no ensino.

Verificamos que, atualmente, vivemos em um mundo dinâmico e repleto de alternativas, sendo assim, as formas de aprendizado mais inovadoras e com o estabelecimento de novos conceitos devem ser incentivadas e aplicadas de forma coerente para que o discente sinta maior interesse pelos conteúdos curriculares. Assim, tal importância é dada à medida que o aluno os observa, não apenas através de analogias, mas também por meio da aplicabilidade efetiva no mundo real em que vivemos.

Desta forma, percebemos que através de uma trilogia, a qual possui referências e influências das mais diversas, podemos encontrar várias informações que contemplam um auxílio, principalmente, ao aprendizado tecnológico. Isto faz com que, não apenas determinados discentes identifiquem-se mais com o tema, pois já têm uma tendência natural pela tecnologia, mas também se pode promover o aprendizado de quem não possui tal intimidade já que ao menos em Matrix (1999) a tecnologia é levada muito em consideração, no entanto, tudo relacionada ao próprio mundo da Matrix, que para seus personagens é real.

As passagens da trilogia trazem recursos de ensino muito maiores que os próprios personagens, ou seja, a conclusão básica é que devemos utilizar mais as passagens do filme que os personagens em si, a fim de transferirmos conceitos e conhecimentos de várias áreas.

Neste ponto, nota-se que a interdisciplinaridade da saga é muito boa, ou seja, podemos utilizar em várias áreas do conhecimento que tenham interação direta com as 
tecnologias e/ou fatos abordados, principalmente em cursos de computação, porém com possibilidades de estudos matemáticos, físicos, filosóficos e religiosos.

Enfim, podemos verificar que uma alternativa assim pode não apenas influenciar os discentes a formarem pensamentos análogos para fixação de determinadas informações curriculares, mas também vemos que é possível conseguir isto de forma mais prazerosa e divertida através do cinema.

\section{Referências}

BBC's Greatest English Books list - http://www.bbc.co.uk/arts/bigread/top100.shtml- Acesso em 06/2013

BAKEMAN, R., \&Gottman, J.M. (1986). Observing interaction: An introduction to sequential analysis. Cambridge: Cambridge University Press.

CAREY, Martin - Cinema's Scarlet Letters: the MPAA Rating System and Film Education in the Christian University - Christian Perspectives in Education, 2010, Vol.3(2), p.1.

CARRAHER, D.W. O Papel do Computador na Aprendizagem. Acesso, 3 (5): 19-21, 1992.

CLAREMBEAUX, Michel - Educación en cine: memoria y patrimonio Film Education: Memory and Heritage - Comunicar, 2010, Vol.XVIII(35), p.25.

COSTA, Marcos A. Ensino Apoiado com Técnicas de Desenvolvimento Ágil através de um Objeto de Aprendizagem. Tese de Mestrado - URI - Santo Ângelo, 2012.

IMDB - Internet Movie Database - http://www.imdb.com - Acessos em 06/2013

KAWAMURA, Regina. Linguagem e Novas Tecnologias. In: ALMEIDA, Maria José P.M. de, SILVA, Henrique César da. (Orgs.). Linguagens, Leituras e Ensino da Ciência. Campinas: Mercado das Letras. 1998.

KETTERER, David. Canadian Science Fiction and Fantasy. Indiana University Press, 1992.

MANN, J., Have, T. T., Plunkett, J. W., \&Mesiels, S. J. (1991). Time sampling: A methodological critique. Child Development, 62, 227- 241.

MONTEIRO, Eduardo B., REZENDE, Flavia. 1993. Informática e Educação: panorâmica da área segundo artigos dos periódicos nacionais de educação. Tecnologia Educacional, v.22, n.110, 111, p.42-49, jan/abr.1993.

PIASSI, Luís Paulo e PIETROCOLA, Maurício - Ficção científica e ensino de ciências: para além do método de 'encontrar erros em filmes' - Universidade de São Paulo - Resumo. Ciência \& Educação, v. 14, n. 2, p. 271-282, 2008.

PIASSI, Luís Paulo e PIETROCOLA, Educação e Pesquisa, Vol.35, 2009. p.525-540.

PRETTO,Nelson de Luca. Uma escola sem/com futuro - educação e multimídia, Campinas, São Paulo: Ed. Papirus, 1996.

RAYMOND, Eric. "The Early Hackers". A Brief History of Hackerdom. Thyrsus Enterprises, 2000. http://www.catb.org/ esr/writings/cathedral-bazaar/hacker-history/ar01s02.html 
SILVA, Marco. Cibercultura e educação: a comunicação na sala de aula presencial e online. (Dossiê ABCiber). Revista FAMECOS [1415-0549] Silva, Marco yr: 2008 iss: 37 pg:69.

RottenTomatoes - http://www.rottentomatoes.com- Acessos em 06/2013

WIKI-Wikipedia- http://www.wikipedia.org - Acessos em 06/2013 